\title{
Development of a Portable Mass Spectrometric System for Determination of Isotopic Composition of Solid Uranium Samples Using Fluorine Volatilization
}

Final Report (September 30, 1994)

by

Gary Loge
Laser Diagnostics

\begin{abstract}
Using hardware and materials supplied by LANL, a prototype quadrupole mass spectrometer system designed for portable field analysis of isotopic composition of solid uranium samples was assembled and tested. The system contained the capability for fluorine volatilization of solid uranium samples with gas introduction, which was successfully tested and demonstrated using $100 \mathrm{mg}$ samples of $\mathrm{U}_{3} \mathrm{O}_{8}$. Determination of precision and accuracy for measuring isotopic composition was performed using isotopic standards.

Use with soil samples containing uranium were also attempted. Silicates in the soil forming $\mathrm{SiF}_{4}$ were found to be a kinetic bottleneck to the formation of $\mathrm{UF}_{6}$. This could be avoided by performing some sort of chemical separation as a pre-treatment step, which was demonstrated using nitric acid.
\end{abstract}

\section{DISCLAIMER}

This report was prepared as an account of work sponsored by an agency of the United States Government. Neither the United States Government nor any agency thereof, nor any of their employees, makes any warranty, express or implied, or assumes any legal liability or responsibility for the accuracy, completeness, or usefulness of any information, apparatus, product, or process disclosed, or represents that its use would not infringe privately owned rights. Reference herein to any specific commercial product, process, or service by trade name, trademark, manufacturer, or otherwise does not necessarily constitute or imply its endorsement, recommendation, or favoring by the United States Government or any agency thereof. The views and opinions of authors expressed herein do not necessarily state or reflect those of the United States Government or any agency thereof. 


\section{DISCLAIMER}

Portions of this document may be illegible in electronic image products. Images are produced from the best available original document. 


\section{Construction of Mass Spectrometer-Fluorination Apparatus}

The quadrupole mass spectrometer used for this system was a standard residual gas mass analyzer with the capability of detecting masses up to $200 \mathrm{amu}$. It was equipped with a faraday cup detector and an electron multiplier. The quadrupole was contained in standard conflat flanged vacuum components with the electron source at the center of a conflat cross.

\section{A. Pumping System}

Several different pumping systems were used. The initial system consisted of a getter pump with a Welch single stage rotary mechanical pump that had an ultimate vacuum of $100 \mathrm{~m}$ Torr. This mechanical pump served two purposes, to initially pump out the getter pump and to pump out the fluorination line. When the fluorinating agent, $\mathrm{ClF}_{3}$, or the product, $\mathrm{UF}_{6}$, was pumped out of the line, a charcoal trap was used to remove most of the corrosive gases before reaching the pump oil.

A getter pump was chosen because of its light weight and ruggedness, which would be required for a portable system. However, this system was found to be inadequate for the mass analysis when used with the single stage mechanical pump. For the sake of convenience, the getter pump was replaced with a small turbomolecular pump, which was more than adequate for the pumping requirements. The single stage mechanical pump was used as the fore pump for the turbo pump with a valve used to isolate the turbopump when the mechanical pump was used to pump out the fluorination line. Most of the results reported were obtained using this setup, however, it was seen as more of a research convenience rather than as a prototype design since it added considerably to the weight and size of the system. 
One problem experienced with the turbomolecular pump was its unreliability in this application. Two pumps crashed during a six month period. It is not clear as to the reason for this, a poor pump design, the harsh chemicals pumped, or inadequate fore pumping. Also, the Welch single stage mechanical pump was found to be not very corrosion resistant when used to pump out the fluorination line, even with the charcoal trap. After several months of use it was discovered that the mechanical pump was badly corroded with some plastic interior parts actually melted by residual $\mathrm{ClF}_{3}$ that passed through the charcoal trap. Also this pump had only a 0.1 Torr ultimate vacuum, which may have been inadequate for forepumping the turbomolecular pumps that crashed. This rough pump was also inadequate for pumping the argon from the getter pump, which would leave about $10^{-3}$ Torr of argon.

While still using the second turbomolecular pump, a two stage mechanical pump with a ultimate vacuum of $1 \times 10^{-4}$ Torr was used along with a molecular sieve trap to prevent backstreaming of the pump oil vapor. This second turbo pump subsequently crashed, which forced the use of the getter pump. At this time a two valve system was used to prevent any backward introduction of gas from the manifold into the mass spectrometer chamber and getter pump. Concurrently, the charcoal trap used to collect the $\mathrm{ClF}_{3}$ was replaced with a soda lime trap. This reacts very strongly with $\mathrm{ClF}_{3}$. When more than a few liter-Torr of $\mathrm{ClF}_{3}$ is pumped through this trap the valve should be opened slowly to prevent overheating of the trap.

When the two stage mechanical pump was used to pump out the getter pump, a pressure reading of about $10^{-4}$ Torr total pressure was observed in the mass spectrometer chamber. This was accomplished by closing the pump valve to the manifold and opening the valve to the getter pump very slowly. The " $\mathrm{T}$ " section of this line just before the molecular sieve trap was slow to pump down but could be opened to the getter pump several minutes after isolating from the fluorination line. Once the getter pump was evacuated to $10^{-4}$, the valve to the getter pump was closed and all mass peaks except 40 and 
20 would slowly diminish. With this procedure, the getter pump could reach an ultimate vacuum of $5 \times 10^{-6}$, with the peak at 40 having a Faraday cup current of $3 \times 10^{-9}$ amps.

Using this getter pump some attempt was made to demonstrate the detection of $\mathrm{UF}_{6}$ using 5 Torr of $\mathrm{UF}_{6}$ in the manifold. Starting at the base pressure of $5 \times 10^{-6} \mathrm{Torr}$, the leak valve was opened to allow $1 \times 10^{-5}$ Torr into the chamber with the electron multiplier used. $\mathrm{UF}_{6}$ signals were seen with the electron multiplier voltage set to $1600 \mathrm{~V}$ and the current scale at $6 \times 10^{-11} \mathrm{amp}$. However, the pressure in the chamber slowly built-up to $2.3 \times 10^{-5}$ in about five minutes due to argon in the sample. This build-up of argon was even worse if the manifold that containing the 5 Torr of $^{U_{6}}$, was not completely pumped down to remove all argon before introducing the sample.

\section{B. Computer Acquisition of Isotope Ratios}

The residual gas analyzer software operating under DOS has the capability to save data files of several types. Most of the mass scan data taken for this project were saved as analog files. The program allowed a series of spectra to be automatically saved to the hard

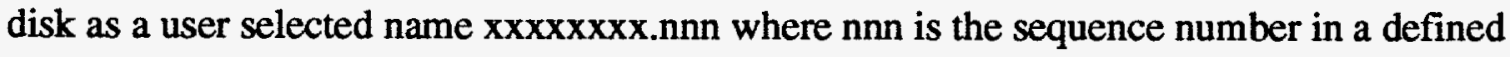
series of spectra that is added by the program. The time interval between spectra and the total number of spectra are defined by the user. The scan time, which determines the signal to noise ratio, is set by the user in the main menu parameters.

Another way to save data to the hard disk that is useful for obtaining isotope ratios is to select the partial pressure mode of data acquisition. This is done by selecting the mode option from the control menu. Once in the partial pressure mode, up to six peaks can be monitored continuously. The default mode is an updated table of the intensity of the selected peaks. By selecting the display option and then the trend option, a plot of the selected peaks vs. time can be obtained. This can be saved to a hard disk file by first giving the file a name by selecting the file option, then enabling disk writing by selecting the disk button, then starting data acquisition by selecting the enable button. When finished 
taking data, the file can be converted to an ASCII data file using the file handling option that is accessed from the control option. This file can then be imported into a spreadsheet for further data analysis, such as time averaging of the data for better signal to noise ratio and selecting any time slice in the histogram.

\section{Separating $\mathrm{CF}_{3}$ from $\mathrm{UF}_{6}$}

The purpose of this separation is to have a lower operating pressure for the mass spectrometer with enough partial pressure of $\mathrm{UF}_{6}$ to allow for accurate measurements of the isotope ratio. The limiting operating pressure was about $10^{-5}$ Torr when using the electron multiplier, so if a $\mathrm{UF}_{6}$ partial pressure of $10^{-7}$ Torr is required for accurate isotope measurements, the "separation" in the fluorination manifold would have to yield at least $1 \%$ $\mathrm{UF}_{6}$ to obtain a useful measurement. With the corrosive gases used in these studies, a lower total pressure also increased the lifetime of the electron source filament.

$\mathrm{ClF}_{3}$ has a higher vapor pressure than $\mathrm{UF}_{6}$, which can be used to separate the two gases after reaction with solid uranium compounds to form $\mathrm{UF}_{6}$. This separation is more complete at lower temperatures. For example, at $25^{\circ} \mathrm{C}$, the vapor pressure of $\mathrm{ClF}_{3}$ is 2500 Torr while the vapor pressure of $\mathrm{UF}_{6}$ is 70 Torr. At $-10^{\circ} \mathrm{C}$ the vapor pressure of $\mathrm{UF}_{6}$ drops to about 7 Torr while the vapor pressure of $\mathrm{ClF}_{3}$ is still several hundred torr. At $-40^{\circ} \mathrm{C}$, which would be the preferred operating temperature for distillation separator, the vapor pressure of $\mathrm{UF}_{6}$ is less than one Torr, while the vapor pressure of $\mathrm{ClF}_{3}$ is still greater than 100 Torr. At lower temperature the loss of $\mathrm{UF}_{6}$ when pumping away the $\mathrm{ClF}_{3}$ is also minimized.

In practice, this distillation separation was performed in the same sample cylinder that was used for the reaction to form $\mathrm{UF}_{6}$. After reaction to convert the solid uranium to $\mathrm{UF}_{6}$, the sample was chilled to $0^{\circ} \mathrm{C}$ with an ice bath or to $-10^{\circ} \mathrm{C}$ with a thermoelectric cooler and heat sink. At these temperatures the $\mathrm{UF}_{6}$ is not completely condensed ( $>1 \mathrm{mTorr}$ vapor pressure) so the $\mathrm{ClF}_{3}$ could not be simply pumped out with the sample cylinder open to the 
vacuum line. A compromise procedure was used that allowed most of the $\mathrm{ClF}_{3}$ to be removed with some loss of $\mathrm{UF}_{6}$. This was done by evacuating the manifold line (volume approx. $10 \mathrm{ml}$ ) then isolating it from the vacuum pump and opening the value to the cooled sample tube. This allowed $1 / 2$ of the $\mathrm{ClF}_{3}$ to expand into to manifold along with about one Torr of $\mathrm{UF}_{6}$. The valve was then closed after a short time to prevent further sublimation of the $\mathrm{UF}_{6}$ condensed in the sample tube. Then the manifold was evacuated and the procedure repeated one or two more times. Then the sample tube was allowed to warm to room temperature. After evacuation of the manifold, the valve to the sample tube was opened. Ideally this procedure should reduce the $\mathrm{ClF}_{3}$ partial pressure a factor of 4 or 8 , while reducing the $\mathrm{UF}_{6}$ partial pressure 2 or 3 Torr. The actually ratio was lower than expected because not all of the $\mathrm{U}_{3} \mathrm{O}_{8}$ was reacted in the $1-2 \mathrm{hr}$ reaction time. (Heating the sample cylinder to about $40^{\circ} \mathrm{C}-60^{\circ} \mathrm{C}$ with the thermoelectric cooler and a negative voltage would probably speed this up considerably).

A reported in the last quarterly report, a higher heat capacity thermoelectric cooler (TEC) was used in attempt to reach a lower operating temperature of the cooling system. The new TEC had about twice the heat or cooling capacity, but when it was used in place of the smaller TEC the lowest temperature reached was $-4^{\circ} \mathrm{C}$, which is not as low as the smaller TEC, which reached a temperature of $-10^{\circ} \mathrm{C}$. The reason for this is probably due to poor insulation. The larger TEC was larger than the metal mounting plate, so could not be as well insulated. However, using this larger TEC with a better insulation design should allow at least $-20^{\circ} \mathrm{C}$ operation.

\section{Measurement of Solid Uranium Compound Isotope Ratios}

From previous studies, it was shown that the fluorination of $\mathrm{U}_{3} \mathrm{O}_{8}$ was relatively rapid. $\mathrm{U}_{3} \mathrm{O}_{8}$ is also readily available is isotopic standard mixtures, so it was used in all the studies. For a typical measurement, the fluorination procedure was to put approximately $50 \mathrm{mg}$ of the $\mathrm{U}_{3} \mathrm{O}_{8}$ sample into a $10 \mathrm{ml}$ stainless steel (316 alloy) sample cylinder which 
has been cleaned in a nitric acid solution in an ultrasonic cleaner, dried, and passivated using 200 Torr of $\mathrm{ClF}_{3}$ vapor for about one hour. After connecting the sample tube containing the uranium sample to the fluorination manifold, the air was evacuated.

Several procedures for the fluorination reaction were tried. For a small uranium sample the $\mathrm{ClF}_{3}$ vapor was the limiting reactant. $50 \mathrm{mg}$ of $\mathrm{U}_{3} \mathrm{O}_{8}$ is $59 \mu$ mole. For complete fluorination of this sample the overall reaction stochiometry is assumed to be

$$
9 \mathrm{ClF}_{3}+\mathrm{U}_{3} \mathrm{O}_{8}->3 \mathrm{UF}_{6}+4 \mathrm{ClO}_{2} \mathrm{~F}+5 \mathrm{ClF}
$$

which requires 9 mole of $\mathrm{ClF}_{3}$ for every mole of $\mathrm{U}_{3} \mathrm{O}_{8}$. For a $100 \mathrm{mg} \mathrm{U}_{3} \mathrm{O}_{8}$ sample the required amount of $\mathrm{ClF}_{3}$ for complete reaction of $50 \mathrm{mg}$ of $\mathrm{U}_{3} \mathrm{O}_{8}$ is $1.01-\mathrm{Torr}$ at $22^{\circ} \mathrm{C}$. In a $10 \mathrm{ml}$ sample tube with approximately $2 \mathrm{ml}$ of volume between the tube and valve, the required amount of $\mathrm{ClF}_{3}$ is 167 Torr. For a typical reaction procedure 600 Torr of $\mathrm{ClF}_{3}$ was put in the 10 sample tube along with $50-100 \mathrm{mg}$ of $\mathrm{U}_{3} \mathrm{O}_{8}$ and allowed to react for 1 to two hours.

Isotope ratio measurements were taken for two isotopic mixtures of $\mathrm{U}_{3} \mathrm{O}_{8}$. One was an enriched sample of $50 \% 235 \mathrm{U}$ and the other was a natural abundance isotopic sample, which should be $0.58 \% 235 \mathrm{U}$. The results are shown in the figures in the first quarterly report of this project. These were not taken using the partial pressure data acquisition mode, which should allow a more accurate ratio determination.

As a final note, the current condition of the line needs some work before further fluorination reactions of solid uranium compounds can be conducted. The Swaglok fitting on the valve that connects to the $10 \mathrm{ml}$ sample tube has become unusable from too much use with continual changing of the sample tube. It no longer holds a vacuum and allows air to enter. This destroys the fluorine passivation and converts $\mathrm{UF}_{6}$ to $\mathrm{HF}$ and $\mathrm{UO}_{2} \mathrm{~F}_{2}$ due to reaction with water in air. 


\section{Separation of UF 6 from Soils}

Several attempt were made to obtain isotopic ratio measurement of soil samples contaminated with uranium. Controlled soil samples were made using normal soil that was sifted to remove all the larger particles to which was added weighed amounts of $\mathrm{U}_{3} \mathrm{O}_{8}$. Typically $1 \%$ or $0.1 \%$ uranium containing samples were used. The first procedure was to use $\mathrm{ClF}_{3}$ in an attempt to completely fluorinate the soil sample. This was found to be unsatisfactorily slow. Even after 36 hours of reaction only a small fraction of the soil sample was converted to volatile fluorides. The mass analysis did show the presence of $\mathrm{SiF}_{4}$ as $\mathrm{SiF}_{3}$ ions. No evidence of $\mathrm{UF}_{6}$ was seen. It is possible that the fluorination of silicon was a kinetic bottleneck, with any $\mathrm{UF}_{6}$ reacting with silicon (or silicates) to form $\mathrm{SiF}_{4}$, which is more thermodynamically stable.

The next attempt was to use hydrogen fluoride in a pre-treatment step. HF is known to react with silicon to form $\mathrm{SiF}_{4}$, but does not form $\mathrm{UF}_{6}$ with uranium compounds. Before using anhydrous HF, which is difficult to work with because of its high vapor pressure, demonstration experiments were performed using $50 \% \mathrm{HF}$ in water. This should dissolve the silicon to form $\mathrm{SiF}_{4} \cdot \mathrm{H}_{2} \mathrm{O}$, and $\mathrm{U}_{3} \mathrm{O}_{8}$ should react to give $\mathrm{UF}_{4}$ and $2 \mathrm{UO}_{2} \mathrm{~F}_{2}$. After doing this, green colored crystals of $\mathrm{UF}_{4}$ were seen and all the black $\mathrm{U}_{3} \mathrm{O}_{8}$ was removed by reaction with $50 \%$ HF which presumably was converted to soluble $\mathrm{UO}_{2} \mathrm{~F}_{2}$, but the soil was again very slow to react. For the aqueous HF the possibility of removing the uranium sample from the soil as $\mathrm{UO}_{2} \mathrm{~F}_{2}$ that is water soluble is possible. However, the presence of water in the fluorine gas handling line was found to spoil the fluorine passivation, which meant that the water could not be simply pumped away leaving $\mathrm{UO}_{2} \mathrm{~F}_{2}$.

The next attempted separation method was to use carbonate solutions to extract the uranium from the soil. A solution of $0.5 \mathrm{M}$ sodium carbonate and $0.5 \mathrm{M}$ sodium bicarbonate was used. This solution has been previously shown to remove up to $85 \%$ of uranium in soil. However, this solution when used with the soil samples with $1 \% \mathrm{U}_{3} \mathrm{O}_{8}$ 
did not extract any of the $\mathrm{U}_{3} \mathrm{O}_{8}$. It was efficient for extracting a reddish colored compound which is probably iron oxide.

The final and apparently successful method to extract uranium from soils was to use concentrated nitric acid. One gram of soil with $1 \%$ uranium was washed with $10 \mathrm{ml}$ of concentrated nitric acid for several minutes. The acid was then decanted and allowed to dry under a heat lamp. The remaining yellowish solid was found to be radioactive, indicating the presence of uranium. These samples are still awaiting flurination tests and are stored in centrifuge tubes in the hood.

\section{Conclusions}

The procedure has been shown to work well with solid uranium compounds. Only a small amount of $\mathrm{ClF}_{3}$ is needed to generate enough $\mathrm{UF}_{6}$ for isotopic analysis. For the isotopic analysis of uranium in contaminated soils, a pretreatment separation is needed. It appears that nitric acid will work, but further work is needed.

The original design using a getter pump will work with an adequate roughing pump capable of $10^{-4}$ Torr.

Further work is also needed to obtain more accurate isotope ratio measurements using the partial pressure data acquisition mode. 